specific gene determinants to chromosome 21. Perhaps the nature of gene action and phenotypic expression in mongolism will be understood long before the bicentenary of Dr Down's paper comes round.

W. M. Court Brown

\section{HUMAN INHERITANCE}

\section{Genetics of Man}

By Paul Amos Moody. Pp. viii +444. (New York: W. W. Norton and Company, Ine., 1967.) \$7.50.

THIs book is an introduction to the principles of genetics and to inheritance in man. Based on a course of elementary lectures, it is suitable for medical students and those who want to know more about man. Each chapter has retained the characteristics of a lecture, offering problems for further study and a list of references to original works. The book remains a collection of lectures, and the references are not collected at the back and the names of the authors do not occur in the index.

The introduction to theories of inheritance is more successful than the outline of human cytogenetics. It is doubtful whether a reader would gain an adequate knowledge of the structure and behaviour of chromosomes to appreciate the applied science that is referred to as genetic engineering. He should find, however, the gradual introduction to theories of probability and methods of calculating inheritance an excellent groundwork for the study of human pedigrees.

A prospective reader need not be put off by the figures and formulae he may see as he turns the pages, for Professor Moody has succeeded in his aim of avoiding the intricacies of mathematics.

There is a simple but adequate exposition of twin studies. This leads to well balanced appreciations of the inheritance of intelligence, natural selection in human populations, the genetics of race and, finally, to a chapter on genetic counselling. Genetic counselling is becoming the fashion and those who think it has reached an advanced stage might read the last chapter for a straightforward factual explanation of its difficulties and limitations.

Wilma George

\section{OUR ABNORMAL CHROMOSOMES}

\section{Human Population Cytogenetics}

By W. M. Court Brown. (North-Holland Research Monographs: Frontiers of Biology, Vol. 5.) Pp. xii +107 (31 tables, 25 plates). (Amsterdam: North-Holland Publishing Company, 1967.) $40 s$.

Dr W. M. Court Brown and his colleagues at the Medical Research Council Clinical Effects of Radiation Unit have played a unique part in the history of human cytogenetics. Dr Court Brown was active in the subject from the start of its recent efflorescence (1956), and the unit which he heads is now the largest one for the mass study of human chromosomes in the world. Moreover, the geographical position of the unit is such that it is able to survey, if it wishes, the whole population in the sealimited Edinburgh-Glasgow axis. It not only has a comprehensive filing system for all karyotypes studied, but also a team of social workers trained to follow up any case in which the subsequent history, or familial studies, are likely to be of interest. For these reasons the unit has been able to collect a unique mass of information on the incidence of chromosomal variations and abnormalities in a large population.

This book gathers together in one volume several topics on which reports have hitherto been scattered in various journals. It does not claim to be comprehensive; rather it reflects the problems which have been of particu- lar interest to the author and his colleagues in the past few years. The topics fall under three main headings: the incidence of clearly visible abnormalities (and variants) in the mitotic chromosomes in a normal population; the problem of the chromatin-positive male; and the role and nature of the $Y$ chromosome.

The findings are such as might be expected from a large-scale study of those morphological peculiarities of chromosomes which can clearly be seen with the aid of the microscope. The incidence of the various anomalies found is clearly listed, and the clinical manifestations of the resultant phenotypes are defined briefly; it is also shown how chromosomal alterations may be inherited in families.

In the first chapter the increase of aneuploidy with age is clearly dealt with; then the author considers the controversial subject of chromatid aberrations (these are so dependent on cultural conditions that he can only say that the whole status of chromatid abnormalities in preparations from population surveys remains to be evaluated). The conclusions about chromosome aberrations and their relation to environmental chromosome damaging agents are not much more definite, although the extensive work (of Buckton and others) on the long-term effects of radiation on the behaviour of lymphocytes has given us much basic information about the consequences of chromosomal damage. Finally, in this chapter, the author considers inherited variants in autosomes found in phenotypically normal individuals; these are found especially in the acrocentric chromosomes of groups $D$ and $G$ and in pair 16 . It is surprising that no specific mention is made of the chromosomal satellites, for these exhibit morphological variations and it has been shown that abnormally long ones can on occasion be inherited. Perhaps the subject has been generally disregarded because of early erroneous ideas of others on the use of the satellites in chromosomal classification (now abandoned) and the relationship of long satellites to certain diseases which had been proposed on rather slender evidence.

The second chapter contains a most valuable contribution to the literature on chromatin-positive males (who do not necessarily, as Dr Court Brown points out, present with Klinefelter's syndrome), and a study of the ways in which they present for diagnosis and of their ultimate fate.

The third chapter deals with the $Y$ chromosome; two findings of particular interest are the evidence that there may be a sex-determining locus on the short arm of the $Y$ (this is based on the phenotypes of individuals found to have abnormal $Y$ chromosomes) and the well known recent discovery of the high incidence of tall $X Y Y$ males in institutions reserved for unusually violent and aggressive individuals.

In the last chapter the author considers chromosomal rearrangements in the population and relates them to the classical theories of Muller and others relating to radiationinduced rearrangements. Here again the main types of rearrangements found are catalogued together with their incidence, which totals (on the basis of mitotic studies) about 0.5 per cent in the normal population. The author indicates, however, that the recent meiotic studies of McIlree and others in the Clinical Effects of Radiation Unit show clearly that this figure is likely to be an underestimate, for they have brought to light probable heterozygosities in the chromosomes not visible in mitotic cells.

Altogether this is a monograph which will be essential in the library of any human geneticist or cytogeneticist. It gives the basic data on the incidence and genetic behaviour of such gross alterations in the autosomes as can be seen by microscopic inspection. Abnormalities of the sex chromosomes are not dealt with as a whole, because these were thoroughly documented in an earlier monograph from this unit. The layout of this work is particularly clear and easy for reference. Cytologists 